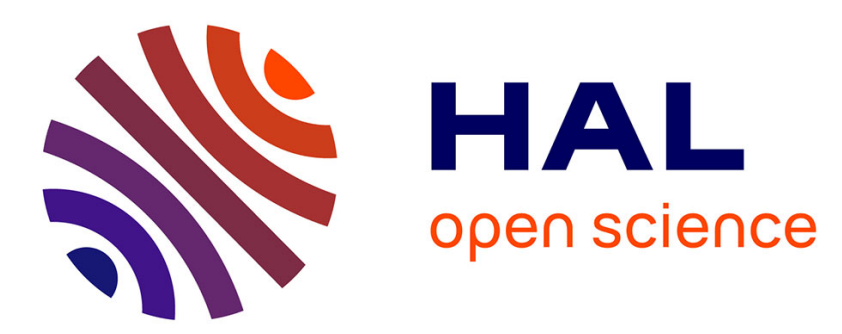

\title{
Modelling of thermal oxidation of phosphite stabilized polyethylene
}

Fatma Djouani, Emmanuel Richaud, Bruno Fayolle, Jacques Verdu

\section{To cite this version:}

Fatma Djouani, Emmanuel Richaud, Bruno Fayolle, Jacques Verdu. Modelling of thermal oxidation of phosphite stabilized polyethylene. Polymer Degradation and Stability, 2011, 96 (7), pp.1349-1360. 10.1016/j.polymdegradstab.2011.03.014 . hal-02455174

\section{HAL Id: hal-02455174 \\ https://hal.science/hal-02455174}

Submitted on 25 Jan 2020

HAL is a multi-disciplinary open access archive for the deposit and dissemination of scientific research documents, whether they are published or not. The documents may come from teaching and research institutions in France or abroad, or from public or private research centers.
L'archive ouverte pluridisciplinaire HAL, est destinée au dépôt et à la diffusion de documents scientifiques de niveau recherche, publiés ou non, émanant des établissements d'enseignement et de recherche français ou étrangers, des laboratoires publics ou privés. 


\title{
Modelling of thermal oxidation of phosphite stabilized polyethylene
}

\author{
Fatma Djouani, Emmanuel Richaud*, Bruno Fayolle, Jacques Verdu \\ Arts et Metiers ParisTech, CNRS, PIMM, 151 boulevard de l'Hôpital, 75013 Paris, France
}

Keywords:

Polyethylene

Thermal ageing

Phosphite

Phosphate

Kinetic modelling

\begin{abstract}
A B S T R A C T
The thermal oxidation behaviour of polyethylene films stabilized by various weight ratios of organophosphites (Irgafos 168) has been studied at selected temperatures. The duration of the induction period was found to increase proportionally with the stabilizer concentration, even at temperatures as low as $80^{\circ} \mathrm{C}$. Particular attention was paid to the phosphite-phosphate conversion during the induction period. A kinetic model, involving volatile and partially soluble hydroperoxide decomposers, was developed in order to simulate these results. With the use of kinetic parameters that can be at least tentatively justified from theoretical considerations, this model gave simulations in reasonable agreement with the experimental observations for stabilizer depletion and carbonyl formation. Of particular note is the fact that, even for non-trivial results such as the shape of the phosphite versus phosphate concentration plots, or phosphate build-up, there was also a quite good agreement.
\end{abstract}

\section{Introduction}

Aryl phosphites are extensively used as stabilizers in the melt processing of polyolefins. They are capable of limiting the colour development that is induced during polymer processing. This is a recognized drawback of quinone species generated from phenolic antioxidants. As discussed below, there is some considerable controversy in the literature regarding the exact nature of the stabilization mechanism involved.

According to Hiatt et al. [1], the phosphorous non-linking electron pair can directly interact with an oxygen atom of the hydroperoxide group and this leads to an assisted hydrogen transfer:<smiles>[R]OO[PH](C)(C)P(C)CC</smiles>

A cage mechanism involving various possible intermediates has also been proposed:

\footnotetext{
* Corresponding author.

E-mail address: emmanuel.richaud@paris.ensam.fr (E. Richaud).
}<smiles>C[PH]1(C)CC1</smiles><smiles>[R]OO</smiles>

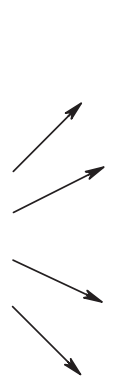<smiles>C[P+]1(C)CCC1</smiles><smiles>[R]OC1([Ge])CC1</smiles><smiles>[R]O[P+](C)(C)O</smiles><smiles>CCP(C)(C)(C)O</smiles>
$\left.{ }^{\circ} \mathrm{O}-\mathrm{R}\right]_{\text {cage }}$<smiles>[R]OP(C)(C)(C)CO</smiles>

Scott [2] proposed a mechanism involving [ $\left.\rightarrow \mathrm{P}^{\circ}-\mathrm{OH}:::{ }^{\circ} \mathrm{OR}\right]$. However, due to the fact that there are similar electron densities on both the oxygen atoms in the hydroperoxides [3], there is also the possibility that an equivalent amount of $\left[\rightarrow \mathrm{P}^{\circ}-\mathrm{OR}:::^{\circ} \mathrm{OH}\right]$ could also form. In fact, this radical mechanism leads to efficient stabilization only if the radicals do not escape from the cage. This, according to Pobeminskii and Buchachenko, is in fact the case [4]. Nevertheless, recent research on polyethylene oxidation [5] indicates that even macroradicals are capable of escaping from the cage and this in turn makes this particular radical mechanism questionable. Another radical mechanism was proposed by Habicher and coworkers [6]. They concluded that phosphites convert $\mathrm{POO}^{\circ}$ into $\mathrm{PO}^{\circ}$ and $\mathrm{PO}^{\circ}$ into $\mathrm{P}^{\circ}$. However, an ionic mechanism involving the $\left[\rightarrow \mathrm{P}^{+}-\mathrm{OR}::{ }^{-} \mathrm{OH}\right]$ 
intermediate as first postulated by Walling and Rabinowitz [7] or $\left[\rightarrow \mathrm{P}^{+}-\mathrm{OH}:::^{-} \mathrm{OR}\right]$ as later reported by Denney et al. [8], is in fact more likely. Recently, Habicher and Bauer $[9,10]$ reviewed the various possible pathways for the reaction of phosphite:

(1) the decomposition of hydroperoxides

(2) the reaction with radicals

(3) hydrolysis generating a phenol derivative

(4) the chelation of metal residues

(5) the direct reaction with molecular oxygen

In addition to the pathways proposed, it is possible to envisage other mechanistic options:

- For example, a mechanism in which the duration of the induction period is increased principally because a lower quantity of unstable moieties is formed during processing.

- Alternatively a mechanism in which the main increase of induction period is the reaction of residual phosphite remaining after processing with species involved in the polymer oxidation chain mechanism.

Phosphite stabilization has been studied at high temperatures in particular because it is here that it is particularly effective [11-13]. Phosphites are most commonly used in combination with phenols because they give a strong synergistic effect [14-18]. Predicting phosphite efficiency, modelling phenol-phosphite synergy in PE stabilization or examining the interactions between the phosphite stabilization and other kinds of stabilizers [19], all require an indepth study of the phosphite stabilization on its own. In addition, completing the previously established model for pure PE thermal oxidation $[5,20]$ and modelling phosphite stabilization itself would be most advantageous in coming to any conclusions regarding the overall mechanisms involved. Adding the reactions, (1) (2) (3) (4) (5) together is not a major issue in itself since the system of differential equations derived from this mechanistic scheme is easily solved thanks to numerical tools. However, any assessment of the relative contribution of each of these mechanisms through the corresponding five kinetic parameters would be extremely difficult because an infinity of mathematical solutions for simulating the experimental results is in fact possible.

The aim of the present study was to find evidence for the major pathway of phosphite consumption from experimental results over a specific temperature range. In addition, as illustrated elsewhere $[21,22]$, we will derive a mechanistic scheme with the minimal number of adjustable parameters, (i.e. relatively simple), but physically consistent and then assess the resulting kinetic parameters from the experimental data using an inverse approach.

\section{Experimental}

\subsection{Materials}

The selected PE powder (supplied by Borealis) was stabilizer free, as confirmed by the absence of any induction period in the control DSC isothermal thermograms at $180{ }^{\circ} \mathrm{C}$.

The phosphite stabilizer, Irgafos 168 (CAS $N^{\circ}$ 31570-04-4, supplied by Ciba SC) had the following structure:

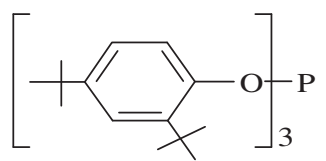

The DSC of the stabilizer powder gave a melting temperature of $185.5^{\circ} \mathrm{C}$ and a melting enthalpy of $73 \mathrm{~J} \mathrm{~g}^{-1}$.
Table 1

Molar extinction coefficients of phosphite and carbonyl groups.

\begin{tabular}{llll}
\hline $\begin{array}{l}\text { Wave number } \\
\left(\mathrm{cm}^{-1}\right)\end{array}$ & Compound & $\varepsilon\left(\mathrm{l} \mathrm{mol}^{-1} \mathrm{~cm}^{-1}\right)$ & Comment \\
\hline 1191 & $\mathrm{P}-\mathrm{O}$ & 330 & For Irgafos 168 \\
966 & $\mathrm{O}=\mathrm{P}(\mathrm{V})--$-[O-Aryl $]_{3}$ & 938 & For TriArylPhosphate \\
850 & $\mathrm{P}(\mathrm{III})--[\mathrm{O}-\mathrm{Aryl}]_{3}$ & 318 & For Irgafos 168 \\
772 & $\mathrm{P}-\mathrm{O}$ & 440 & For Irgafos 168 \\
\hline
\end{tabular}

Compounded samples were prepared by pouring a solution of additive in dichloromethane onto the PE powder. The stabilizer concentration and the solution volume were adjusted in order to obtain the desired stabilizer concentration in the PE. After solvent evaporation at room temperature, thick films, about $100 \mu \mathrm{m}$, were compression moulded at $200{ }^{\circ} \mathrm{C}$ under $250 \mathrm{MPa}$ pressure for $30 \mathrm{~s}$ using a commercially available laboratory press (Gibrite Instrument).

The initial stabilizer concentration in the PE amorphous phase was calculated using the following equation:

$[\mathrm{Stab}]=\frac{1}{1-x_{\mathrm{C}}} \cdot \frac{\rho_{\mathrm{PE}}}{M_{\mathrm{Stab}}} \cdot x_{\mathrm{Stab}} \cdot f_{\mathrm{Stab}}$

where:

- $x_{C}$ is the crystallinity ratio; taken as equal to 0 in molten state and 0.5 in solid state.

- $\rho_{\mathrm{PE}}$ is the polymer density (935 $\mathrm{g} \mathrm{l}^{-1}$ ).

- $M_{\text {Stab }}$ is the stabilizer molar mass $\left(\mathrm{g} \mathrm{mol}^{-1}\right)$.

- $x_{\text {Stab }}$ is the global stabilizer weight ratio in the polymer.

- $f_{\text {Stab }}$ is the stabilizer functionality, i.e. the number of active groups per molecule.

Some comparison experiments were carried out with:

- Other phosphites: PEPQ (CAS 38613-77-3), Irgafos 38 (CAS 145650-60-8), Irgafos 126 (CAS 26741-53-7) all supplied by Ciba SC.

- A commercial triphenyl phosphate (purity > 99\%, reference 241288 supplied by Sigma Aldrich).

- PE films stabilized with other phenolic antioxidants Irganox 1010 (CAS 98584-37-3) and Irganox 1076 (CAS 2082-79-3) prepared by the same method.

- The product of the direct reaction between Irgafos 168 and cumyl hydroperoxide (reference 513296, supplied by Aldrich). The proposed structure is:

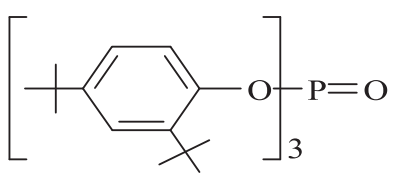

This reaction was performed by progressively adding cumyl hydroperoxide ( $\sim 0.5$ g every $10 \mathrm{~h}$ ) to a refluxing solution of Irgafos 168 (3.25 g) in $50 \mathrm{ml}$ of 1,2-dichloroethylene (analysis grade supplied by Carlo Erba). In order to ensure the total conversion of Irgafos 168, cumyl hydroperoxide was added in excess (5 g). After purification in cyclohexane and storage at room temperature, the brown solid precipitate was collected. Its melting temperature was found to be close to $100{ }^{\circ} \mathrm{C}$ as reported elsewhere [23]. Its melting enthalpy was found to be close to $33.2 \mathrm{~J} \mathrm{~g}^{-1}$. Structural changes due to phosphite-phosphate conversion will be presented in the 'Results' section. 


\subsection{Characterization}

\subsubsection{Fourier transform infrared spectrophotometry}

FTIR spectra of the various PE films were recorded in transmittance mode using a Bruker IFS 28 spectrophotometer; 32 scans at $4 \mathrm{~cm}^{-1}$ resolution. Several absorption bands attributed to Irgafos 168 were observed at 1211, 1191, 850 and $772 \mathrm{~cm}^{-1}[24,25]$. The corresponding molar extinction coefficients determined in this study are presented in Table 1 . The molar absorptivity concentration of Irgafos 168 phosphates $(\text { ArylO })_{3}-\mathrm{P}(\mathrm{V})=\mathrm{O}$ by-products was estimated from PE + triphenyl phosphate films which display a peak at $966 \mathrm{~cm}^{-1}$ of which the molar absorptivity is $9381 \mathrm{~mol}^{-1} \mathrm{~cm}^{-1}$. It will be assumed that the phosphate derived from Irgafos 168 displays similar characteristics. The absorbances of carbonyl compounds resulting from PE oxidation were converted into concentration using the molar absorptivity of chain ketones at $1715 \mathrm{~cm}^{-1}\left(300 \mathrm{l} \mathrm{mol}^{-1} \mathrm{~cm}^{-1}\right)$ [26].

\subsubsection{Determination of the stabilizer concentration using OIT measurements}

Initial and residual stabilizer activities were measured from induction time values obtained by DSC under $0.1 \mathrm{MPa}$ oxygen pressure at $180{ }^{\circ} \mathrm{C}$ (denoted $\mathrm{OIT}_{180}$ in the following); the oxygen flow was $50 \mathrm{ml} \mathrm{min}{ }^{-1}$. The measurements were performed on about $5 \mathrm{mg}$ samples using a Q10 apparatus (TA Instruments). OIT 180 corresponds to the onset of the exothermal signal due to polymer decomposition. Under these conditions, the pure polyethylene OIT $_{180}$ is close to $1 \mathrm{~min}$ and increases with stabilizer concentration (Fig. 1). OIT 180 values versus theoretical stabilizer concentration were plotted. The results are fairly consistent with a straight line. Although data for the lowest stabilizer concentration are under the trend line, this can be rationalized by stabilizer loss during the film preparation (see later).

\subsubsection{HPLC analysis}

Any residual stabilizer and its by-products were removed from the polymer films using a classical extraction procedure: about $0.5 \mathrm{mg}$ of PE was refluxed in chloroform for $16 \mathrm{~h}$. The solution was then filtered and directly analysed by HPLC using a Waters $717+$ apparatus. The stationary phase was grafted silane C18 maintained at $35^{\circ} \mathrm{C}$. Detection was performed using a Waters 2414 Refractive Index $\left(T_{\text {detector }}=40^{\circ} \mathrm{C}\right)$ and Photo Diode Array 2998. This allowed the monitoring of the UV spectra of the mobile phase in the 200-400 nm range every second. Samples were injected in ACN (HPLC plus grade, supplied by Carlo Erba); flow was $1 \mathrm{ml} \mathrm{min}^{-1}$.

A comparison of chromatograms of Irgafos 168, and its main reaction product after reaction with cumyl hydroperoxide is given in Fig. 2. As expected, the retention time of the latter is lower than

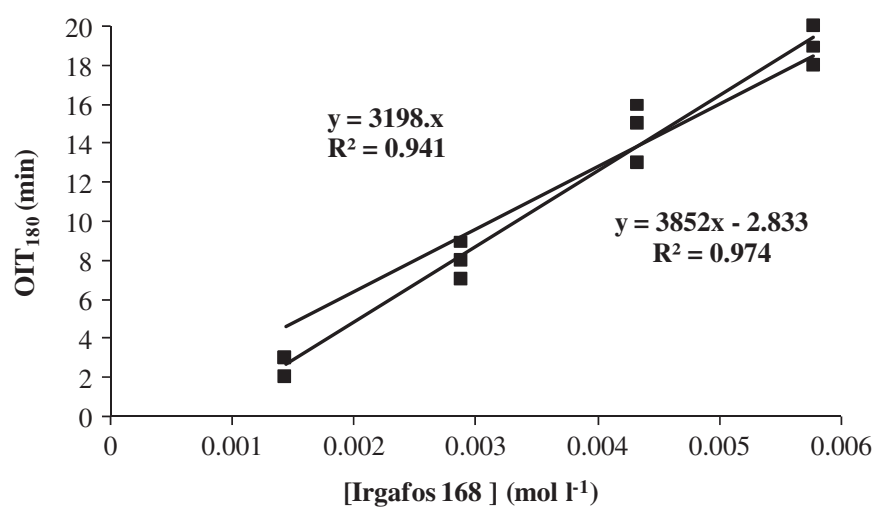

Fig. 1. $\mathrm{OIT}_{180}$ changes as a function of Irgafos 168 concentration (irrespective of amorphous and crystalline phase).

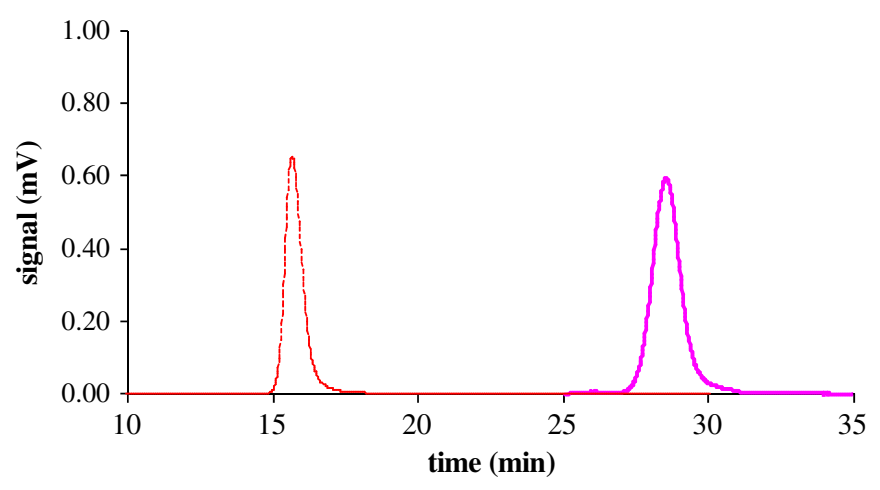

Fig. 2. Chromatograms of Irgafos 168 (--) and its main oxidation product after reaction with cumyl hydroperoxide (- - ) using detection at $270 \mathrm{~nm}$.

for the starting phosphite; a more polar product eluted in an apolar stationary phase.

\subsubsection{UV analysis}

2.2.4.1. Solutions. Phosphites were analysed in solution using the PDA detector of the HPLC/GPC. Examples of spectra of the various phosphites (in THF) are presented in Fig. 3a. Phosphites and phosphates are compared in Fig. 3b. Aryl phosphites are characterized by the aromatic ring absorption at $270 \mathrm{~nm}$ and a maximal absorption at ca. $207 \mathrm{~nm}$ accompanied by a shoulder at about $225 \mathrm{~nm}$. The cut-off of which is close to $245 \mathrm{~nm}$. The organophosphate UV absorption spectrum differs significantly from the phosphite ones especially in the absence of the shoulder at $225 \mathrm{~nm}$.

2.2.4.2. Thin films. UV spectra in transmittance mode were acquired using a Lambda 35 apparatus (Perkin Elmer) driven by
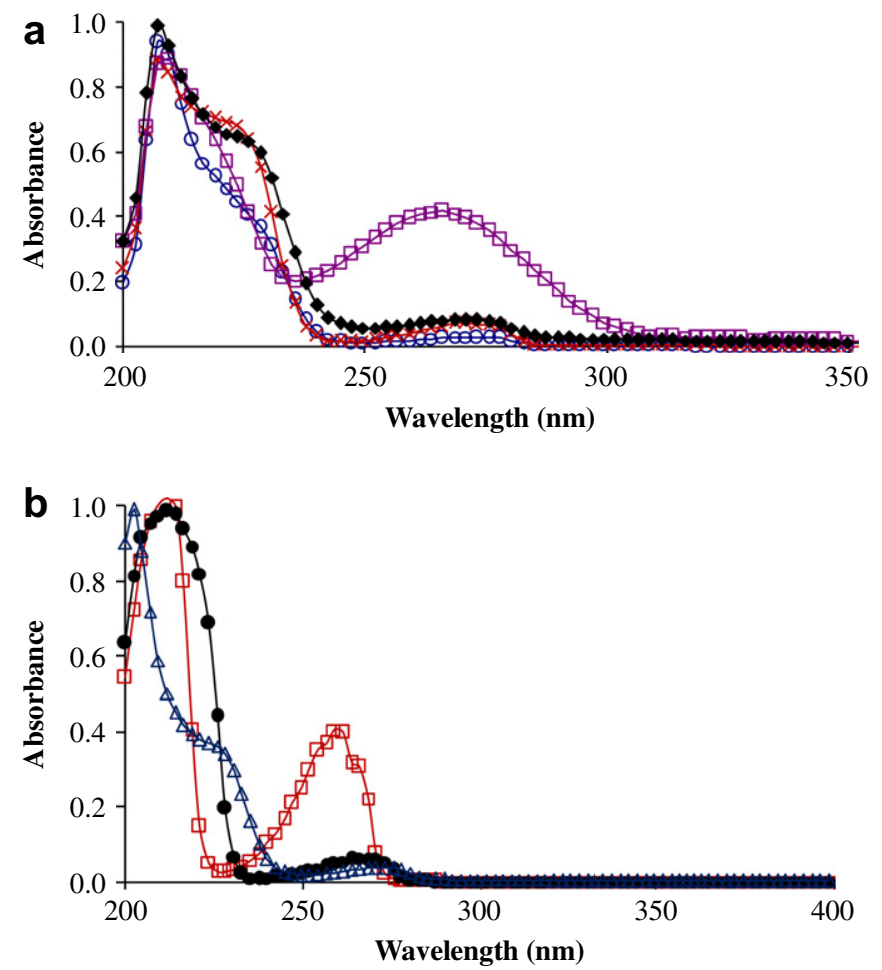

Fig. 3. Normalized UV spectra of various phosphites: $\times$ : Irgafos $126, \bigcirc$ : Irgafos $38, \square$ : PEPQ : Irgafos 168 (a) and normalized UV spectra of $\triangle$ : Irgafos $168 \bullet$ : phosphate derived from Irgafos 168 (see "Materials" section), $\square$ : Triphenyl phosphate (b). 

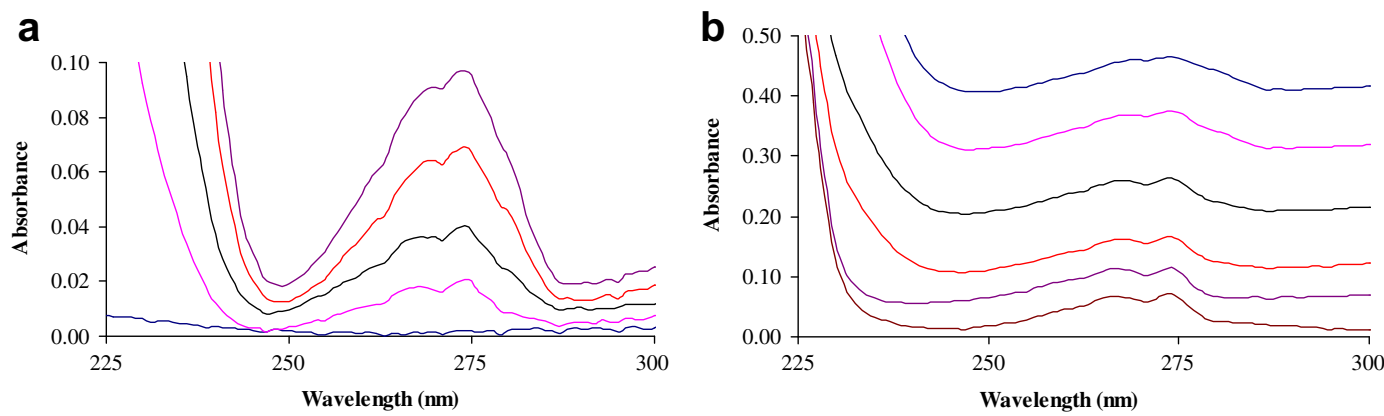

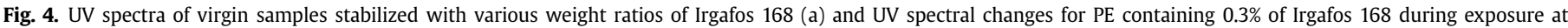
$80{ }^{\circ} \mathrm{C}(\mathrm{b})$.

Perkin Elmer UV Winlab software. UV spectra of pure and stabilized PE samples are shown in Fig. 4.

\subsubsection{TGA measurements}

The stabilizer volatility was measured in a series of experiments under isothermal conditions under nitrogen $\left(50 \mathrm{ml} \mathrm{min}^{-1}\right)$ using a TGA Q500 driven by Q Series Explorer. About $10 \mathrm{mg}$ of pure stabilizer or a single foil (for PE + Irgafos 168 films) were placed in aluminium pans and submitted to a $20^{\circ} \mathrm{C} \mathrm{min}^{-1}$ ramp from room temperature to the selected measurement temperature.

\subsection{Thermal ageing}

Ageing of polyethylene films was carried out in air at both $80^{\circ} \mathrm{C}$ and $120^{\circ} \mathrm{C}$ in ventilated ovens. The kinetics of the reaction between Irgafos 168 and oxygen were studied by submitting a solution of Irgafos 168 in 1,2,4 trichlorobenzene (ReagentPlus ${ }^{\mathrm{TM}}$ grade supplied by Sigma Aldrich) as the non-reactive solvent to high oxygen pressure (here $1.7 \mathrm{MPa}$ ) at $80{ }^{\circ} \mathrm{C}$ in temperature-controlled autoclaves.

\section{Results}

\subsection{Carbonyl formation}

FTIR spectroscopy is an analytical technique particularly suited to following the kinetics of polymer-based reactions. A judicious choice of bands means that the progress of the reaction can be easily followed through the appearance or disappearance of relevant functional groups. In this study, a broad band appears in the $1680-1850 \mathrm{~cm}^{-1}$ range indicating the formation of various carbonyl-containing products. In addition to identifying the

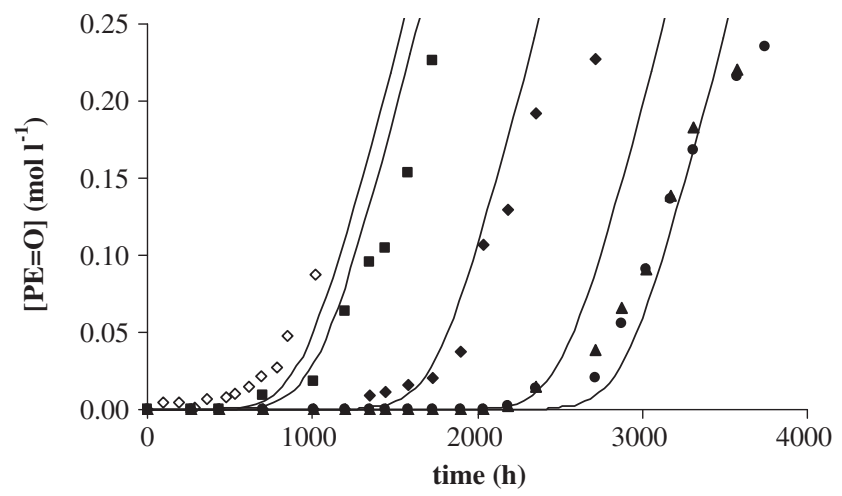

Fig. 5. Carbonyl formation at $80{ }^{\circ} \mathrm{C}$ under air for pure $\mathrm{PE}(\diamond)$, $\mathrm{PE}+0.1 \%(\boldsymbol{\nabla})$, $\mathrm{PE}+0.2 \%$ $(\bullet), \mathrm{PE}+0.3 \%(\boldsymbol{\Delta}), \mathrm{PE}+0.4 \%$ Irgafos $168(\bullet)$ together with their best kinetic modelling using parameters given in Tables 3 and 4 presence of such groups, it was also possible to translate the absorbance at the peak maximum $\left(1715 \mathrm{~cm}^{-1}\right)$ in terms of the carbonyl concentration using a molar absorptivity of $300 \mathrm{l} \mathrm{mol}^{-1}$ $\mathrm{cm}^{-1}$. The carbonyl concentration was plotted against ageing time in Fig. $5\left(80^{\circ} \mathrm{C}\right)$ and Fig. $6\left(120^{\circ} \mathrm{C}\right)$. From the results shown in these figures it can be seen that the curves indicate:

- An induction period whose duration is an increasing function of the phosphite concentration.

- A sharp auto-acceleration at the end of the induction period.

- In certain cases there is a clear final rate decrease; especially for the initial phosphite concentrations of 0.2 and $0.4 \%$.

Interestingly, the maximum rate of carbonyl formation appears almost independent of the initial amount of stabilizer. This feature is characteristic of the so-called "sacrificial" stabilizers. These are typically hydroperoxide decomposers or peroxy radical scavengers such as hindered phenols. This is in contrast to "regenerative" stabilizers such as hindered amine-based ones [27,28].

\subsection{Stabilizer consumption}

The HPLC chromatograms of the products extracted from the PE films are presented in Fig. 7. The data shown make it possible to reach some specific conclusions. Of particular note are the following points: only two species are observed, the phosphite with a retention time at ca. $28 \mathrm{~min}$ and the corresponding phosphate eluted at ca. $16 \mathrm{~min}$. This is attributed to the apparently unique phosphite oxidation by-product. The phosphites disappear progressively during exposure while the phosphates accumulate concomitantly. In the experiment with PE $+0.4 \%$ Irgafos 168 , just

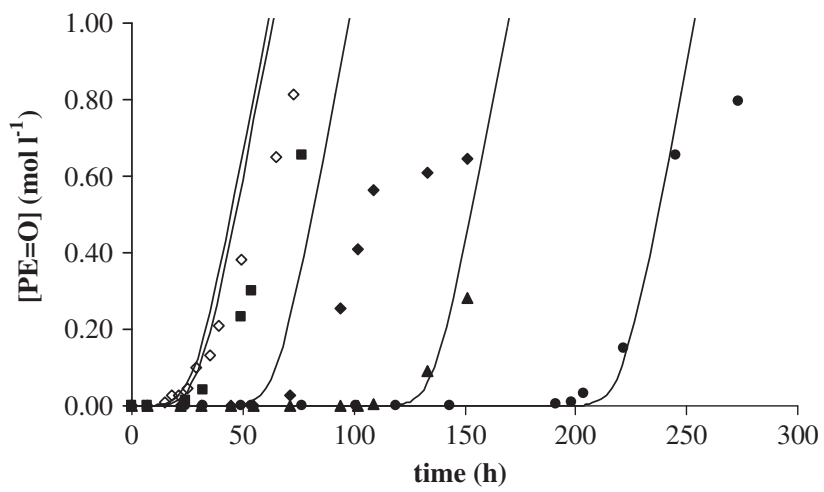

Fig. 6. Carbonyl formation at $120{ }^{\circ} \mathrm{C}$ under air for pure $\mathrm{PE}(\diamond), \mathrm{PE}+0.1 \%(\boldsymbol{\square})$ $\mathrm{PE}+0.2 \%(\bullet), \mathrm{PE}+0.3 \%(\boldsymbol{\Delta}), \mathrm{PE}+0.4 \%$ Irgafos $168(\bullet)$ together with their best kinetic modelling using parameters given in Tables 3 and 4. 


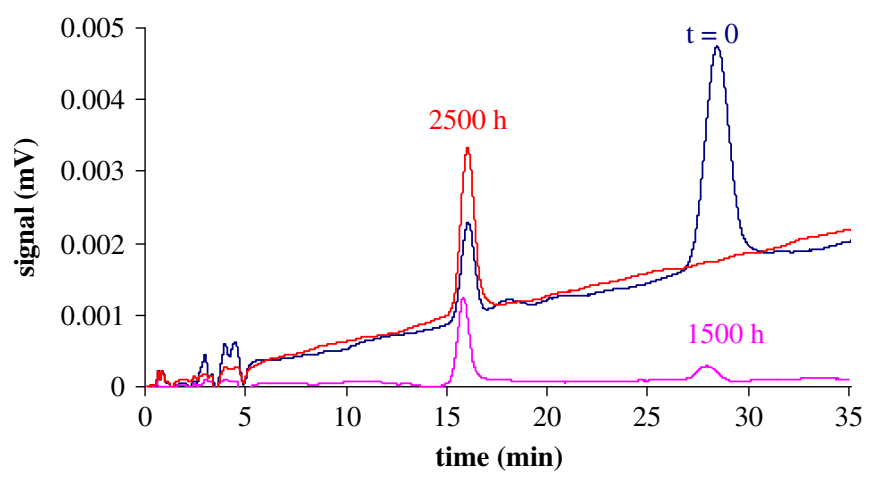

Fig. 7. HPLC chromatograms of extracted solutions for unaged $0.4 \%$ stabilized PE film, PE film after $1500 \mathrm{~h}$ exposure (i.e. before end of induction period) and after $2500 \mathrm{~h}$ (i.e. after the end of induction period).

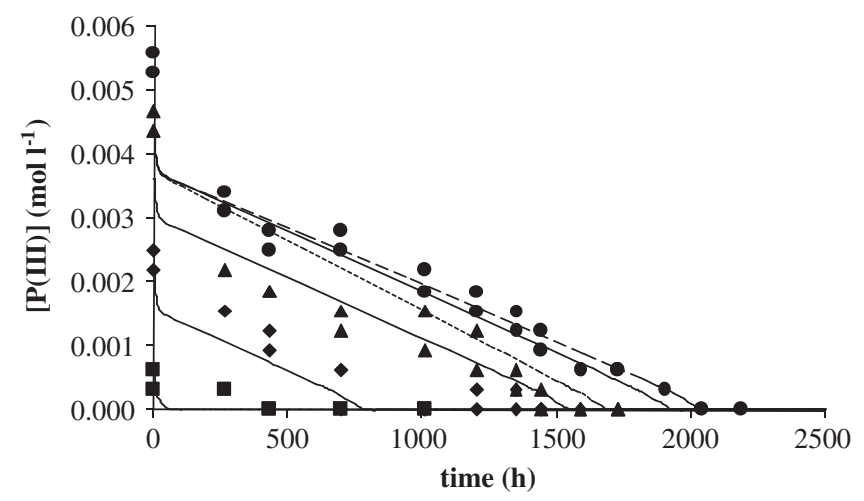

Fig. 8. Residual stabilizer concentrations (from $\mathrm{OIT}_{180}$ measurements) during exposure at $80{ }^{\circ} \mathrm{C}$ under air for PE $+0.1 \%(\boldsymbol{\square}), \mathrm{PE}+0.2 \%(\bullet), \mathrm{PE}+0.3 \%(\boldsymbol{\Delta}), \mathrm{PE}+0.4 \%$ Irgafos 168 ( ) and kinetic modelling using parameters given in Tables 3 and 4 (full lines). corresponds to simulations with $H_{\mathrm{Dec}}=3.10^{-7} \mathrm{~s}^{-1}$, and --- corresponds to simulations with $H_{\text {Dec }}=3.10^{-9} \mathrm{~s}^{-1}$.

before the end of the induction period (about $1500 \mathrm{~h}$ ), the residual phosphite concentration is less than $10 \%$ of the initial value. After $2500 \mathrm{~h}$ of exposure it has totally disappeared. It should be noted that a significant concentration of phosphate was already present at the beginning of the exposure time and this confirms the existence of partial phosphite consumption during the sample processing.

The UV spectra shown in Fig. 4 confirm the progressive disappearance of the shoulder at $235 \mathrm{~nm}$. This agrees with the hypothesis of "progressive transformation" that is conversion of the phosphite into phosphate. Induction time measurements under oxygen at $180{ }^{\circ} \mathrm{C}\left(\mathrm{OIT}_{180}\right)$ were interpreted in terms of residual phosphite concentrations using the following relationship:

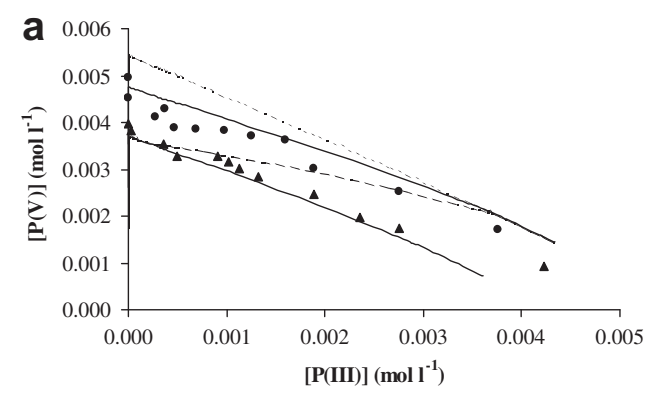

$\mathrm{SE}=\frac{t_{\text {ind }}-t_{\text {ind } 0}}{[\mathrm{Dec}]_{0}}$

where:

- SE is the Stabilizer Efficiency factor $\left(\mathrm{h} 1 \mathrm{~mol}^{-1}\right)$ calculated at $180^{\circ} \mathrm{C}$ from Fig. 1.

- $t_{\text {ind }}$ and $t_{\text {indo }}$ are respectively the induction times values for stabilized and non-stabilized samples.

- $[\mathrm{Dec}]_{0}$ is the initial stabilizer concentration calculated by Eq. (1).

Phosphite consumption kinetic curves for the exposure at $80^{\circ} \mathrm{C}$ are presented in Fig. 8. There is noticeable scatter in the data points. The stabilizer concentration decreases almost linearly until its complete disappearance towards the end of the induction period. At the highest stabilizer concentrations ( 0.3 and $0.4 \%$ ), a fast initial decay of about $10^{-3} \mathrm{~mol} \mathrm{l}^{-1}-2.10^{-3} \mathrm{~mol} \mathrm{l}^{-1}$ can be observed.

The data presented in Fig. 10 show the phosphate build-up at $80^{\circ} \mathrm{C}$. The phosphate concentration is seen to increase over the first $2000 \mathrm{~h}$ e.g. for about $3 / 4$ of the induction period duration. The maximum corresponds to about $50 \%$ of the initial phosphite concentration. After $2000 \mathrm{~h}$ exposure, the phosphate concentration decreases slowly. This can be attributed to its physical loss through evaporation. If phosphate is in fact lost through evaporation, then phosphite which is a slightly lighter molecule, is expected to evaporate also, probably at a comparable rate.

The loss of phosphorous-containing products is confirmed by the evidence presented in Fig. 9b where, phosphite (estimated from the $855 \mathrm{~cm}^{-1}$ IR absorption band) and phosphate (from the $966 \mathrm{~cm}^{-1}$ band) concentrations have been added and their sum plotted against exposure times at $80^{\circ} \mathrm{C}$. This decrease can be safely attributed to evaporation. Its average rate is of the order $5 \times 10^{-4} \mathrm{~mol} \mathrm{l}^{-1} \mathrm{~h}^{-1}$.

\section{Discussion}

It is pertinent to first compare the stabilizer efficiencies of some common sacrificial antioxidants using the previously defined stabilizer efficiency factor SE calculated by Eq. 2. From the data shown in Table 2, the data shown for the following observations can be made:

(1) The induction time depends not only on the reactivity of the stabilizer but also on its rate of physical loss. This is most probably the reason why distearylthiodipropionate (DSTP) is more efficient than dilaurylthiodipropionate (DLTP). This is also presumably why Irganox 1010 appears more efficient than Irganox 1076, especially at high temperatures. This physical loss

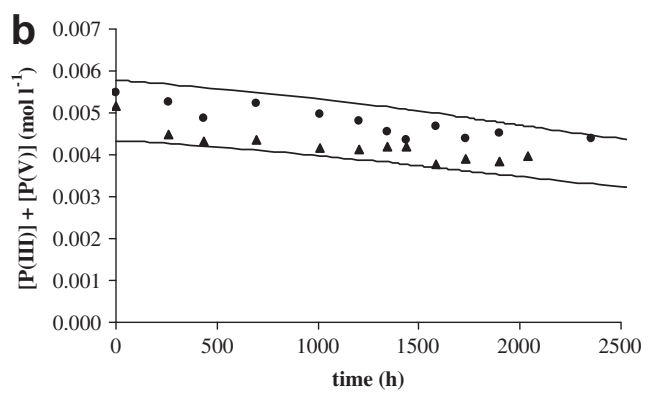

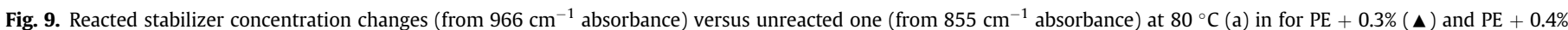

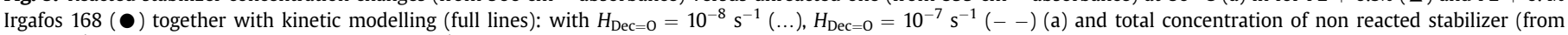
$850 \mathrm{~cm}^{-1}$ absorption) and reacted (from $966 \mathrm{~cm}^{-1}$ absorption) together with kinetic modelling (full lines) using parameters given in Tables 3 and 4 (b). 

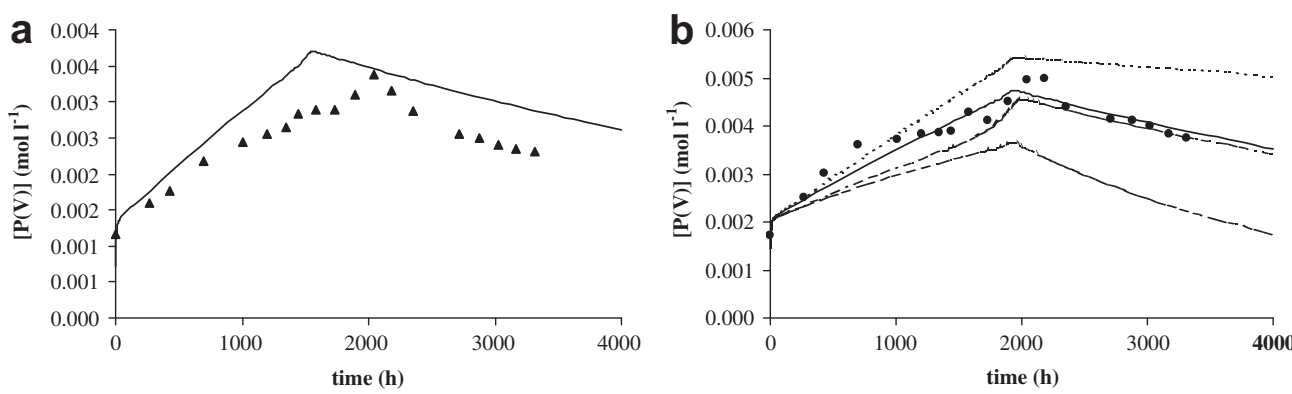

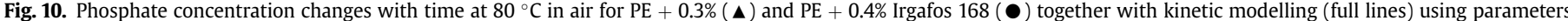

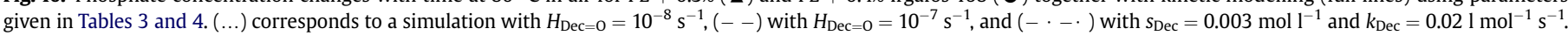

can also explain why the stabilizer efficiency varies nonmonotonically with the temperature.

(2) Despite these complications linked to the combination of chemical consumption and physical loss, it seems that Irgafos 168 is less efficient than sulfides even in the molten state. It is often claimed that phosphites are particularly efficient at high temperatures. In fact that is why they are sometimes called "processing stabilizers". However, from the results reported here, this is not obvious.

It is necessary to first consider the phosphite reactivity. It is interesting to compare simulations made using different mechanism hypotheses with the experimental data. The principle of these simulation runs has been described elsewhere [22]. In the case of PE oxidation, the mechanistic scheme and the rate constant values determined by Khelidj et al. $[5,20]$ (Table 3 ) are used. Where the stabilization processes are concerned, the model will first consider various mechanistic hypotheses.
As mentioned in the introduction, various mechanisms have been proposed in the literature. These could in fact coexist depending on the experimental conditions [29,30]: hydrolysis generating hindered phenols, radical scavenging, direct reaction with oxygen, metal complexation and hydroperoxide decomposition by a non-radical process.

Hydrolysis will be considered first. In principle, it can be observed for pure stabilizer exposed to a wet atmosphere. No hydrolysis by product was observed. Furthermore, this is confirmed by the fact that no hydrolysis by-products were observed in the HPLC chromatograms (Fig. 7). The hydrolytic stability of Irgafos 168 has also been reported by both Ortuoste et al. [31] and Tocháček and Sedlář [32]. Hence, stabilization processes involving phosphite hydrolysis will not be taken into account in subsequent kinetic analysis.

A radical scavenging mechanism involving the reduction of $\mathrm{POO}^{\circ}$ into $\mathrm{PO}^{\circ}$ and $\mathrm{PO}^{\circ}$ into $\mathrm{P}^{\circ}$ radical was proposed by Habicher and coworkers [33]:

Table 2

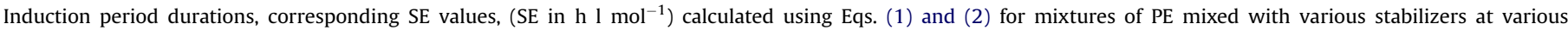
temperatures.

\begin{tabular}{|c|c|c|c|c|c|c|c|c|c|}
\hline \multirow[t]{2}{*}{ Stabilizer } & \multirow[t]{2}{*}{$x(\%)$} & \multicolumn{2}{|l|}{$80^{\circ} \mathrm{C}$} & \multicolumn{2}{|l|}{$120^{\circ} \mathrm{C}$} & \multicolumn{2}{|l|}{$180^{\circ} \mathrm{C}$} & \multicolumn{2}{|l|}{$190{ }^{\circ} \mathrm{C}$} \\
\hline & & $t_{\text {ind }}(\mathrm{h})$ & $\mathrm{SE} \times 10^{-5}$ & $t_{\text {ind }}(\mathrm{h})$ & $\mathrm{SE} \times 10^{-5}$ & $t_{\text {ind }}(\mathrm{h})$ & SE & $t_{\text {ind }}(\mathrm{h})$ & SE \\
\hline DLTP & 0.10 & & & 300 & 0.8 & $0.22 *$ & 107 & 0.08 & 46 \\
\hline \multirow[t]{2}{*}{$\mathrm{M}=514 \mathrm{~g} \mathrm{~mol}^{-1}$} & 0.20 & & & 750 & 1.0 & $0.62 *$ & 164 & 0.23 & 64 \\
\hline & 0.50 & & & 800 & 0.4 & $1.07 *$ & 115 & 0.42 & 46 \\
\hline DSTP & 0.13 & & & 1500 & 4.2 & $0.47 *$ & 250 & 0.15 & 84 \\
\hline \multirow[t]{2}{*}{$\mathrm{M}=682 \mathrm{~g} \mathrm{~mol}^{-1}$} & 0.26 & & & 1700 & 2.4 & $0.92 *$ & 251 & 0.32 & 89 \\
\hline & 0.65 & & & 3300 & 1.8 & $1.62 *$ & 179 & 0.55 & 62 \\
\hline Irgafos 168 & 0.10 & 1100 & 1.4 & 75 & 0.2 & 0.04 & 42 & & \\
\hline \multirow[t]{3}{*}{$\mathrm{M}=648 \mathrm{~g} \mathrm{~mol}^{-1}$} & 0.20 & 1800 & 1.9 & 75 & 0.1 & 0.14 & 49 & & \\
\hline & 0.30 & 2700 & 2.3 & 125 & 0.1 & 0.26 & 60 & & \\
\hline & 0.40 & 2800 & 1.8 & 125 & 0.1 & 0.31 & 54 & & \\
\hline Irganox 1010 & 0.025 & & & & & & & $0.39 * *$ & 491 \\
\hline \multirow[t]{7}{*}{$\mathrm{M}=1176 \mathrm{~g} \mathrm{~mol}^{-1}$} & 0.05 & & & & & & & $0.75 * *$ & 472 \\
\hline & 0.075 & & & & & & & $1.23 * *$ & 516 \\
\hline & 0.10 & & & & & & & $1.77 * *$ & 557 \\
\hline & 0.10 & & & & & & & $0.83 * * *$ & 261 \\
\hline & 0.10 & & & 3400 & 5.3 & 2.6 & 794 & & \\
\hline & 0.20 & & & 5200 & 4.1 & & & & \\
\hline & 0.30 & & & 6900 & 3.6 & 6.4 & 665 & & \\
\hline Irganox 1076 & 0.30 & & & 2100 & 2.0 & 1.3 & 231 & 0.45 & 85 \\
\hline \multirow[t]{10}{*}{$\mathrm{M}=530 \mathrm{~g} \mathrm{~mol}^{-1}$} & 0.50 & & & 2350 & 1.6 & 2.2 & 241 & 0.75 & 51 \\
\hline & 0.03 & & & $1560 * * * *$ & 14.5 & & & & \\
\hline & 0.05 & & & $1800 * * * *$ & 10.1 & & & & \\
\hline & 0.1 & & & $3000 * * * *$ & 10.3 & & & & \\
\hline & 0.025 & & & $1200 * * * * *$ & 13.4 & & & & \\
\hline & 0.05 & & & $2400 * * * * *$ & 16.5 & & & & \\
\hline & 0.07 & & & $2880 * * * * *$ & 14.2 & & & & \\
\hline & 0.1 & & & $3840 * * * * *$ & 13.2 & & & & \\
\hline & 0.15 & & & $3960 * * * * *$ & 7.4 & & & & \\
\hline & 0.2 & & & $4080 * * * * *$ & 5.8 & & & & \\
\hline
\end{tabular}

* Richaud et al. [21]. ** Latocha et al. [53]. *** Setnescu et al. [54]. *** Schwartzenbach et al. [15]. ****Gugumus [55] . 
Table 3

Elementary reactions for PE thermal oxidation and their kinetic parameters.

\begin{tabular}{|c|c|c|c|c|}
\hline Code & Reaction & Rate constant & Pre-exponential factor & Activation energies \\
\hline $1 \mathrm{u}$ & $\mathrm{POOH} \rightarrow 2 \mathrm{P}^{\circ}+\gamma_{2} \mathrm{PC}=\mathrm{O}$ & $k_{1 \mathrm{u}}$ & $8.0 \times 10^{12} \mathrm{~s}^{-1}$ & $140 \mathrm{~kJ} \mathrm{~mol}^{-1}$ \\
\hline $1 b$ & $\mathrm{POOH}+\mathrm{POOH} \rightarrow \mathrm{P}^{\circ}+\mathrm{POO}^{\circ}+\gamma_{2} \mathrm{PC}=\mathrm{O}$ & $k_{1 \mathrm{~b}}$ & $2.8 \times 10^{9} \mathrm{l} \mathrm{mol}^{-1} \mathrm{~s}^{-1}$ & $105 \mathrm{~kJ} \mathrm{~mol}^{-1}$ \\
\hline 2 & $\mathrm{P}^{\circ}+\mathrm{O}_{2} \rightarrow \mathrm{POO}^{\circ}$ & $k_{2}$ & $1.0 \times 10^{8} \mathrm{lmol}^{-1} \mathrm{~s}^{-1}$ & $0 \mathrm{~kJ} \mathrm{~mol}^{-1}$ \\
\hline 3 & $\mathrm{POO}^{\circ}+\mathrm{PH} \rightarrow \mathrm{POOH}^{\circ}+\mathrm{P}^{\circ}$ & $k_{3}$ & $1.5 \times 10^{10} \mathrm{lmol}^{-1} \mathrm{~s}^{-1}$ & $73 \mathrm{~kJ} \mathrm{~mol}^{-1}$ \\
\hline 60 & $\mathrm{POO}^{\circ}+\mathrm{POO}^{\circ} \rightarrow\left[\mathrm{PO}^{\circ} \mathrm{OP}\right]_{\text {cage }}+\mathrm{O}_{2}$ & $k_{60}$ & $4.9 \times 10^{19} \mathrm{l} \mathrm{mol}^{-1} \mathrm{~s}^{-1}$ & $80 \mathrm{~kJ} \mathrm{~mol}^{-1}$ \\
\hline 61 & {$\left[\mathrm{PO}^{\circ}+{ }^{\circ} \mathrm{OP}\right]_{\text {cage }} \rightarrow$ POOP } & $k_{61}$ & $2.0 \times 10^{6} \mathrm{lmol}^{-1} \mathrm{~s}^{-1}$ & $0 \mathrm{~kJ} \mathrm{~mol}^{-1}$ \\
\hline 62 & {$\left[\mathrm{PO}^{\circ}+{ }^{\circ} \mathrm{OP}\right]_{\text {cage }} \rightarrow \mathrm{POH}+\mathrm{PC}=\mathrm{O}$} & $k_{62}$ & $1.2 \times 10^{5} \mathrm{lmol}^{-1} \mathrm{~s}^{-1}$ & $5 \mathrm{~kJ} \mathrm{~mol}^{-1}$ \\
\hline 63 & {$\left[\mathrm{PO}^{\circ}+{ }^{\circ} \mathrm{OP}\right]_{\text {cage }} \rightarrow 2 \mathrm{P}^{\circ}+2 \gamma_{2} \mathrm{PC}=\mathrm{O}$} & $k_{63}$ & $8.0 \times 10^{12} \mathrm{lmol}^{-1} \mathrm{~s}^{-1}$ & $50 \mathrm{~kJ} \mathrm{~mol}^{-1}$ \\
\hline
\end{tabular}

$\mathrm{POO}^{\circ}+\mathrm{Dec} \rightarrow \mathrm{PO}^{\circ}+\mathrm{Dec}=\mathrm{O}$

$\mathrm{PO}^{\circ}+\mathrm{Dec} \rightarrow \mathrm{P}^{\circ}+\mathrm{Dec}=\mathrm{O}$

Since the radical reactivities are in the order: $\mathrm{POO}^{\circ}<<\mathrm{PO}^{\circ}<\mathrm{P}^{\circ}$, it seems difficult to accept that these processes have any stabilizing effect. Habicher's hypothesis [33] was tested by incorporating this process into the mechanistic scheme using a simplified balanced equation:

$\mathrm{POO}^{\circ}+2 \mathrm{Dec} \rightarrow \mathrm{P}^{\circ}+2 \mathrm{Dec}=\mathrm{O} \ldots\left(k_{\text {Dec }}^{\prime}\right)$

The various simulations shown in Fig. 11 (using with $k_{\text {Dec }}^{\prime}$ close to the values suggested in Refs. $[10,33,34]$ ) confirm our observations that there is no stabilizing effect and that stabilizer consumption is auto-accelerated.

Direct reaction with molecular oxygen can have a stabilizing effect if it is competitive with the $\mathrm{P}^{\circ}+\mathrm{O}_{2}$ reaction. According to Neri et al. [35], this should occur only at temperatures higher than $200{ }^{\circ} \mathrm{C}$ which lie outside the temperature range under investigation here. The absence of phosphite-oxygen reactions was confirmed in a control reaction where the pure stabilizer was exposed to high oxygen pressure at $80{ }^{\circ} \mathrm{C}$ [36]. The results for UV analysis coupled with Gel Permeation Chromatography are shown in Fig. 12. From the data obtained it is clear that no significant change linked to eventual stabilizer oxidation was observed.

A mechanism involving the stabilization through metal complexation has been suggested by several authors [9,34,37]. Induction time values obtained in the current study for pure PE indicate the absence of any marked effect of catalytic species. Thus the stabilization by metal scavenging hypothesis cannot be excluded since such a proof lies outside the scope of this study.

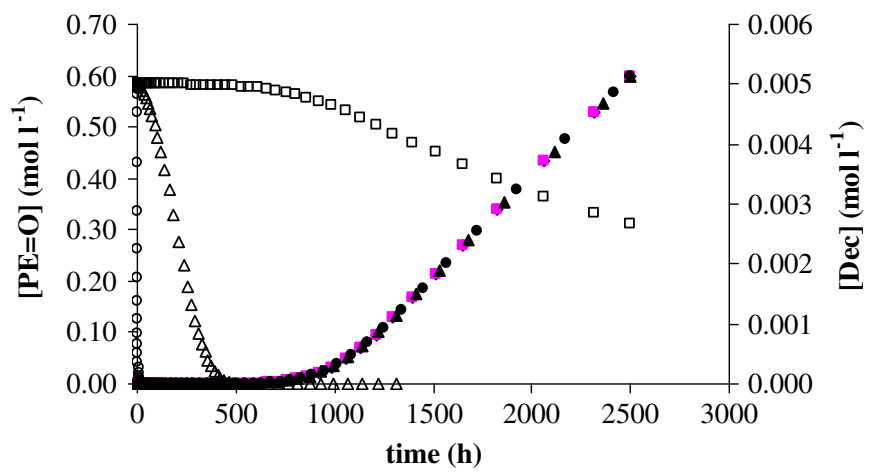

Fig. 11. Kinetic modelling of the «radical mechanism» proposed by Habicher with various rate constants: [Dec $]_{0}=0, k_{\text {Dec }}=01 \mathrm{~mol}^{-1} \mathrm{~s}^{-1}$ ( $\bullet$ : CO build-up), $[\mathrm{Dec}]_{0}=0.005 \mathrm{~mol} \mathrm{l}^{-1}$ and $k_{\text {Dec }}=1 \mathrm{l} \mathrm{mol}^{-1} \mathrm{~s}^{-1}$ ( $\mathbf{\square}$ : CO build-up, $\square$ : stabilizer depletion), $[\text { Dec }]_{0}=0.005 \mathrm{~mol} \mathrm{l} \mathrm{l}^{-1}$ and $k_{\mathrm{Dec}}=10^{3} \mathrm{l} \mathrm{mol}^{-1} \mathrm{~s}^{-1}$ ( $\boldsymbol{\Delta}:$ CO build-up, $\bullet$ : stabilizer depletion), [Dec $]_{0}=0.005 \mathrm{~mol} \mathrm{l}^{-1}$ and $k_{\text {Dec }}=10^{6} 1 \mathrm{~mol}^{-1} \mathrm{~s}^{-1}(\bullet$ : CO buildup, $\bigcirc$ : stabilizer depletion)
It appears therefore, that the most likely stabilization event, and one for which there is in fact a large consensus in the literature $[2,14,17,38-40]$, is the existence of hydroperoxide scavenging by a non-radical process as shown below:

$\mathrm{POOH}+\mathrm{Dec} \rightarrow \mathrm{Dec}=\mathrm{O}+$ inactive products $\left(k_{\mathrm{Dec}}\right)$

Dec denoting the phosphite $\mathrm{P}(\mathrm{III})$ and $\mathrm{Dec}=\mathrm{O}$ the phosphate $\mathrm{P}(\mathrm{V})$. The physical behaviour of the stabilizer should now be considered.

Taking into account the sample thickness (quite thin) and the fact that, during early exposure, physical loss is almost a linear function of time, it can be safely deduced that evaporation controls the whole kinetics of loss.

It should be recalled that stabilizer volatility can be first char-

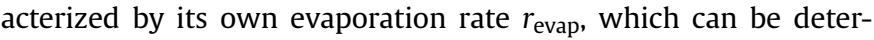
mined by thermogravimetry at relatively high temperatures. In a stabilized polymer, the following rules are usually assumed: when the polymer is saturated by the stabilizer, e.g. when the total stabilizer concentration [Dec] is higher than the equilibrium saturation concentration $[\mathrm{Dec}]_{\text {sat }}$, then the evaporation rate is equal to the evaporation rate of the pure stabilizer $r_{\text {sat. }}$. When the polymer is not saturated by the stabilizer, the evaporation rate is proportional to the stabilizer concentration (denoted by [Dec]). As a consequence, the following equations can be written:

$$
\begin{array}{ll}
{[\mathrm{Dec}] \geq[\mathrm{Dec}]_{\mathrm{sat}}} & \frac{\mathrm{d}[\mathrm{Dec}]}{\mathrm{d} t}=\frac{r_{\mathrm{sat}}}{e} \\
{[\mathrm{Dec}]<[\mathrm{Dec}]_{\mathrm{sat}}} & \frac{\mathrm{d}[\mathrm{Dec}]}{\mathrm{d} t}=\frac{r_{\mathrm{sat}}}{e} \cdot \frac{[\mathrm{Dec}]}{[\mathrm{Dec}]_{\mathrm{sat}}}=H_{\text {Dec }} \cdot[\mathrm{Dec}]
\end{array}
$$

where:

- $r_{\text {sat }}\left(\right.$ in $\mathrm{mol} \mathrm{m}^{-2} \mathrm{~s}^{-1}$ ) is the quantity of stabilizer lost per surface and time unit.

- $e(\mathrm{~m})$ is the sample thickness.

$r_{\text {sat }}$ can be extrapolated from high temperature measurements using Arrhenius's law. But it should be noted that this method is expected to generate relatively high uncertainties (see Appendix A). The results of this extrapolation can be checked as follows: assuming that the phosphate is chemically stable at $80{ }^{\circ} \mathrm{C}-120^{\circ} \mathrm{C}$, one can consider that the decrease in its concentration after ca. $2000 \mathrm{~h}$ of exposure for the highest phosphite concentration under study (Fig. 9) is due to its loss by evaporation alone. This in turn allows the corresponding rate constant $H_{\text {Dec }=0}$ to be determined. Since the phosphite and phosphate molar masses differ only by $2.4 \%$, in a first approach it can be considered that $H_{\text {Dec }} \sim H_{\text {Dec }=0}$. The best-fitting values will be discussed below.

In the case where the overall stabilizer concentration is higher than the concentration at saturation, the following set of hypothesis is used [21]: 


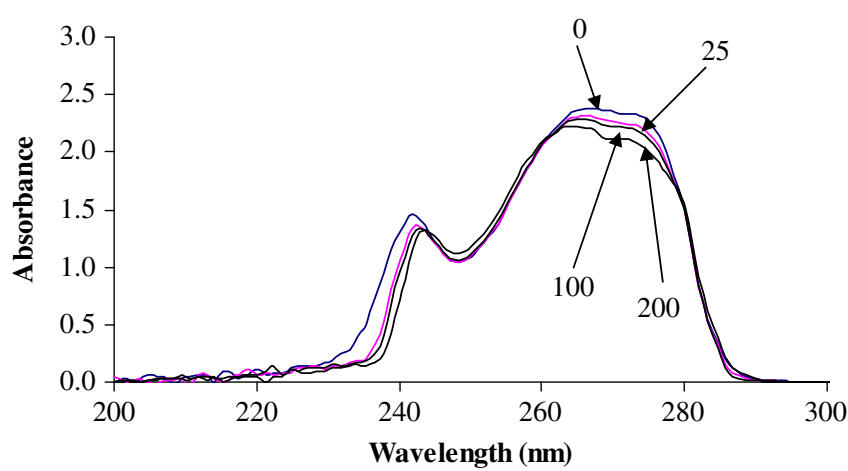

Fig. 12. UV spectra of Irgafos 168 exposed during various durations (indicated by arrows) at $80{ }^{\circ} \mathrm{C}$ in trichlorobenzene solution and then analyzed by GPC in THF solution using PDA detector.

- The concentration of stabilizer dissolved in the matrix is denoted by $[\mathrm{Dec}]_{\text {sol }}$

- If the whole stabilizer content (the average concentration [Dec]) is in excess relative to the saturation (concentration $[D e c]_{\text {sat }}$ ), the excess forms a separated phase (average concentration [Dec $]_{\text {ins }}$ ).

- This separated phase is supposed to be able to promote a fast exchange with the polymer amorphous phase in order to maintain the dissolved concentration at the saturation as long as this excess remains.

- Only the stabilizer dissolved in the polymer matrix actually participates in stabilization events and in evaporation.

Taking these points into consideration it follows that:

If $[\mathrm{Dec}]_{0}<[\mathrm{Dec}]_{\mathrm{sat}}: \quad[\mathrm{Dec}]_{\mathrm{sol} 0}=[\mathrm{Dec}]_{0}$

$$
[\mathrm{Dec}]_{\text {ins } 0}=0
$$

If $[\mathrm{Dec}]_{0} \geq[\mathrm{Dec}]_{\mathrm{sat}}: \quad[\mathrm{Dec}]_{\mathrm{sol} 0}=[\mathrm{Dec}]_{\mathrm{sat}}$

$$
[\mathrm{Dec}]_{\mathrm{ins} 0}=[\mathrm{Dec}]_{0}-[\mathrm{Dec}]_{\mathrm{sat}}
$$

As long as the stabilizer remains in excess, the stabilizer chemical consumption occurs exclusively at the expense of this excess. This can be mathematically modelled using a hyperbolic function (see Eq. (14) and Eq. (15)).

The value of the phosphite concentration at saturation ([Dec $]_{\text {sat }}$ ) can be obtained from experimental data reported in literature or using the kinetic model in an inverse approach (provided that the other kinetic parameters are known). Examples of such calculations are given in Appendix B.

Hydroperoxide decomposition through a phosphite reaction was incorporated into the mechanistic scheme and the corresponding system of differential equations, including those relative to the physical loss by evaporation, was used as a kinetic model. The kinetic scheme is thus composed of the following equations:
Table 5

Possible simulations at $80{ }^{\circ} \mathrm{C}$ with various $k_{\mathrm{Dec}}, s_{\mathrm{Dec}}\left(s_{\mathrm{Dec}}\right.$ not corrected for crystallinity).

\begin{tabular}{lccccc}
\hline$k_{\text {Dec }}\left(1 \mathrm{~mol}^{-1} \mathrm{~s}^{-1}\right)$ & \multicolumn{1}{c}{0.4} & 0.07 & 0.04 & 0.02 & \multicolumn{1}{c}{0.02} \\
\hline$s_{\text {Dec }}(\%)$ & 0.005 & 0.025 & 0.05 & 0.25 & 0.5 \\
\hline$x_{\text {Dec }}=0 \%$ & 939 & 939 & 939 & 939 & 939 \\
$x_{\text {Dec }}=0.1 \%$ & 1059 & 1029 & 1019 & 1006 & 1006 \\
$x_{\text {Dec }}=0.2 \%$ & 1884 & 1751 & 1752 & 1558 & 1558 \\
$x_{\text {Dec }}=0.3 \%$ & 2723 & 2516 & 2605 & 2716 & 2716 \\
$x_{\text {Dec }}=0.4 \%$ & 3143 & 2896 & 3034 & 3389 & 3395 \\
\hline
\end{tabular}

$\begin{aligned} \frac{\mathrm{d}\left[\mathrm{P}^{\circ}\right]}{\mathrm{d} t}= & 2 k_{1 \mathrm{u}}[\mathrm{POOH}]+k_{1 \mathrm{~b}}[\mathrm{POOH}]^{2}-k_{2}\left[\mathrm{P}^{\circ}\right]\left[\mathrm{O}_{2}\right]+k_{3}\left[\mathrm{POO}^{\circ}\right][\mathrm{PH}] \\ & +2 k_{63}\left[\mathrm{PO}^{\circ} \mathrm{OP}\right]_{\mathrm{cage}}\end{aligned}$

$\frac{\mathrm{d}\left[\mathrm{POO}^{\circ}\right]}{\mathrm{d} t}=k_{1 \mathrm{~b}}[\mathrm{POOH}]^{2}+k_{2}\left[\mathrm{P}^{\circ}\right]\left[\mathrm{O}_{2}\right]-k_{3}\left[\mathrm{POO}^{\circ}\right][\mathrm{PH}]$

$$
-2 k_{60}\left[\mathrm{POO}^{\circ}\right]^{2}
$$

$\frac{\mathrm{d}[\mathrm{POOH}]}{\mathrm{d} t}=-k_{1 \mathrm{u}}[\mathrm{POOH}]-2 k_{1 \mathrm{~b}}[\mathrm{POOH}]^{2}-k_{3}\left[\mathrm{POO}^{\circ}\right][\mathrm{PH}]$

$\frac{\mathrm{d}\left[\mathrm{PO}^{\circ}{ }^{\circ} \mathrm{OP}\right]_{\text {cage }}}{\mathrm{d} t}=k_{60}\left[\mathrm{POO}^{\circ}\right]^{2}-\left(k_{61}+k_{62}+k_{63}\right)\left[\mathrm{PO}^{\circ} \mathrm{OP}\right]_{\text {cage }}$

$\frac{\mathrm{d}\left[\mathrm{O}_{2}\right]}{\mathrm{d} t}=k_{60}\left[\mathrm{POO}^{\circ}\right]^{2}-k_{2}\left[\mathrm{P}^{\circ}\right]\left[\mathrm{O}_{2}\right]$

$$
\begin{aligned}
\frac{\mathrm{d}[\mathrm{Dec}]_{\mathrm{sol}}}{\mathrm{d} t}= & -k_{\text {Dec }}[\mathrm{POOH}][\mathrm{Dec}]_{\mathrm{sol}}-H_{\text {Dec }}[\mathrm{Dec}]_{\mathrm{sol}} \\
& +\left(k_{\text {Dec }}[\mathrm{POOH}][\mathrm{Dec}]_{\mathrm{sol}}+H_{\mathrm{Dec}}[\mathrm{Dec}]_{\mathrm{sol}}\right) \cdot \frac{[\mathrm{Dec}]_{\text {ins }}}{[\mathrm{Dec}]_{\mathrm{ins}}+\varepsilon}
\end{aligned}
$$

$\frac{\mathrm{d}[\mathrm{Dec}]_{\text {ins }}}{\mathrm{d} t}=-\left(k_{\mathrm{Dec}}[\mathrm{POOH}][\mathrm{Dec}]_{\mathrm{sol}}+H_{\text {Dec }}[\mathrm{Dec}]_{\mathrm{sol}}\right) \cdot \frac{[\mathrm{Dec}]_{\text {ins }}}{[\mathrm{Dec}]_{\mathrm{ins}}+\varepsilon}$

$\frac{\mathrm{d}[\mathrm{Dec}]}{\mathrm{d} t}=-k_{\mathrm{Dec}}[\mathrm{POOH}][\mathrm{Dec}]_{\mathrm{Sol}}-H_{\mathrm{Dec}}[\mathrm{Dec}]_{\mathrm{sol}}$

$\frac{\mathrm{d}[\mathrm{Dec}=\mathrm{O}]}{\mathrm{d} t} \mathrm{k}_{\mathrm{Dec}}[\mathrm{POOH}][\mathrm{Dec}]_{\mathrm{sol}}-H_{\mathrm{Dec}=\mathrm{O}}[\mathrm{Dec}=\mathrm{O}]$

where $\varepsilon<<[\text { Dec }]_{\text {inso }}$. Here the rate of consumption of the stabilizer excess remains constant until its average concentration remains significantly higher than $\varepsilon$.

\begin{tabular}{|c|c|c|c|c|c|c|c|c|}
\hline \multirow[t]{2}{*}{$T$} & \multicolumn{2}{|c|}{$k_{\text {Dec }}\left(1 \mathrm{~mol}^{-1} \mathrm{~s}^{-1}\right)$} & \multicolumn{2}{|c|}{$[\mathrm{Dec}]_{\text {Sat }}\left(\mathrm{mol} \mathrm{l}^{-1}\right)$} & \multicolumn{2}{|l|}{$H_{\text {Dec }}\left(\mathrm{s}^{-1}\right)$} & \multicolumn{2}{|c|}{$H_{\text {Dec }=0}\left(\mathrm{~s}^{-1}\right)$} \\
\hline & Value & Remark & Value & Remark & Value & Remark & Value & Remark \\
\hline 80 & 0.07 & IM & $7.5 \times 10^{-4}$ & IM & $3 \times 10^{-8}$ & $E$ & $4 \times 10^{-8}$ & IM \\
\hline 120 & 2.5 & IM & - & $\mathrm{T}$ & $5.5 \times 10^{-7}$ & E & $6 \times 10^{-7}$ & IM \\
\hline 180 & 150 & IM & - & $\mathrm{T}$ & $1.75 \times 10^{-5}$ & TGA & - & \\
\hline
\end{tabular}

At $t=0$, the following boundary conditions were used [41]:

$$
-\left[\mathrm{P}^{\circ}\right]=\left[\mathrm{POO}^{\circ}\right]=\left[\mathrm{PO}^{\circ} \mathrm{OP}\right]_{\text {cage }}=0
$$

Table 4

Kinetic parameters used for simulations.

$\mathrm{IM}=$ Inverse method, $\mathrm{T}=$ Theory, $\mathrm{E}=$ Extrapolation and TGA $=$ Thermo Gravimetric Analysis. 


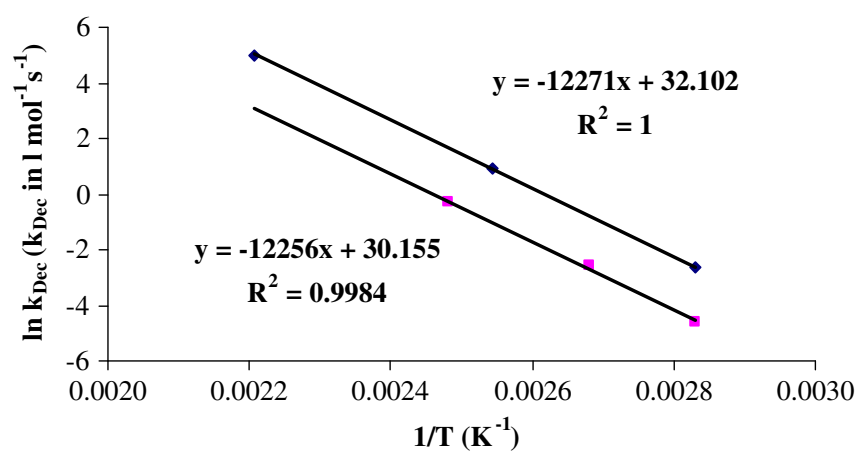

Fig. 13. Arrhenius plot of $k_{\text {Dec }}$ determined in PE ( $\bullet$ ) and PP (

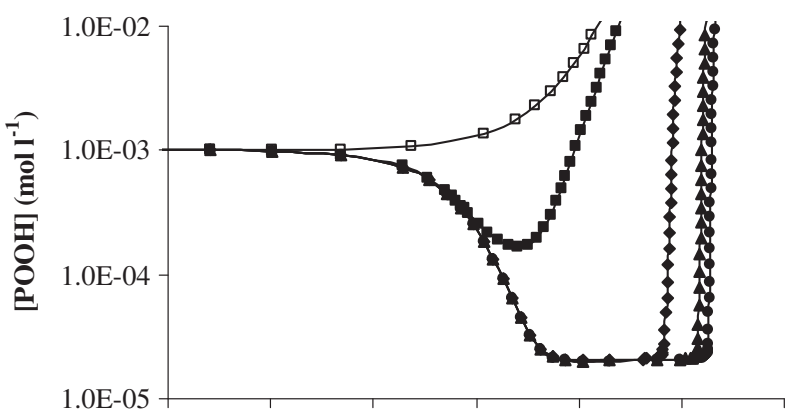

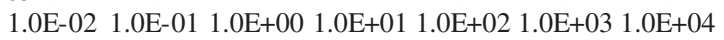
time $(h)$

Fig. 14. Simulation of hydroperoxide concentration curves versus time for exposure at $80{ }^{\circ} \mathrm{C}$ for pure $\mathrm{PE}(\square), \mathrm{PE}+0.1 \%(\boldsymbol{\square}), \mathrm{PE}+0.2 \%(\bullet), \mathrm{PE}+0.3 \%(\boldsymbol{\Delta}), \mathrm{PE}+0.4 \%$ Irgafos 168 ( ) using parameters given in Tables 3 and 4.
- $[\mathrm{POOH}]=[\mathrm{POOH}]_{0}=10^{-3} \mathrm{~mol} \mathrm{l}^{-1}$

$-[\mathrm{PH}]=60 \mathrm{~mol} \mathrm{l}^{-1}$

- $\left[\mathrm{O}_{2}\right]=\mathrm{S}_{\mathrm{O} 2} \times \mathrm{P}_{\mathrm{O} 2}, \mathrm{P}_{\mathrm{O} 2}$ being the partial oxygen pressure and $\mathrm{s}_{\mathrm{O} 2}$ the oxygen solubility in amorphous phase of $\mathrm{PE}$ : $\mathrm{S}_{\mathrm{O} 2}=$ $1.8 \times 10^{-8} \mathrm{~mol} \mathrm{l}^{-1} \mathrm{MPa}^{-1}[42]$.

The measured concentrations $[\mathrm{X}]_{\text {mes }}$ are linked to the really active concentrations in the amorphous phase (corresponding to the output data of the model) $[\mathrm{X}]_{\mathrm{act}}$ by:

$[\mathrm{X}]_{\mathrm{mes}}=\left(1-x_{\mathrm{C}}\right) \times[\mathrm{X}]_{\mathrm{act}}$

$x_{\mathrm{C}}$ being the crystallinity ratio.

Carbonyl groups are believed to originate from alkoxy radicals and have a yield $\gamma_{2}[20]$ so that:

$$
\begin{aligned}
\frac{\mathrm{d}[\mathrm{PE}=\mathrm{O}]}{\mathrm{d} t}= & \left(1-x_{\mathrm{C}}\right) \cdot\left(\gamma_{\mathrm{CO}} k_{1 \mathrm{u}}[\mathrm{POOH}]\right. \\
& +\gamma_{\mathrm{CO}} k_{1 \mathrm{~b}}[\mathrm{POOH}]^{2}+k_{62}\left[\mathrm{PO}{ }^{\circ} \mathrm{OP}\right]_{\mathrm{cage}} \\
& \left.+2 \gamma_{\mathrm{CO}} k_{63}\left[\mathrm{PO}{ }^{\circ} \mathrm{OP}\right]_{\mathrm{cage}}\right)
\end{aligned}
$$

Using an optimization procedure, the parameter values shown in Table 4 were obtained.

The results of simulations obtained with the full kinetic model are shown in Figs. 5, 6, 8, 9 and 10. The consequences of any changes in $H_{\text {Dec }}$ or $H_{\text {Dec }=0}$ are shown in Figs. 8, 9a and 10b. They show that the retained evaporation rates are undoubtedly within a good order of magnitude. The phosphate versus phosphite plot should be a straight line and an expected slope of -1 in the absence of evaporative loss. The experimental value found, however, is closer to -0.75 which is in very good agreement with kinetic model predictions (Fig. 9a). The use of many sets of $k_{\text {Dec }}$, $s_{\text {Dec }}$ should lead to reasonable simulations (Table 5 ). It should be noted that $k_{\text {Dec }}$ has the same order of magnitude as that reported in previous studies $[10,34,38]$. In principle, $s_{\text {Dec }}$ could be adjusted from the shape of the experimental curves but it must be recognised that there is a certain lack of accuracy in the

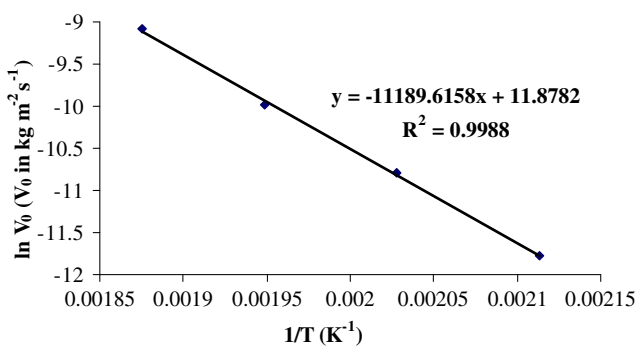

b

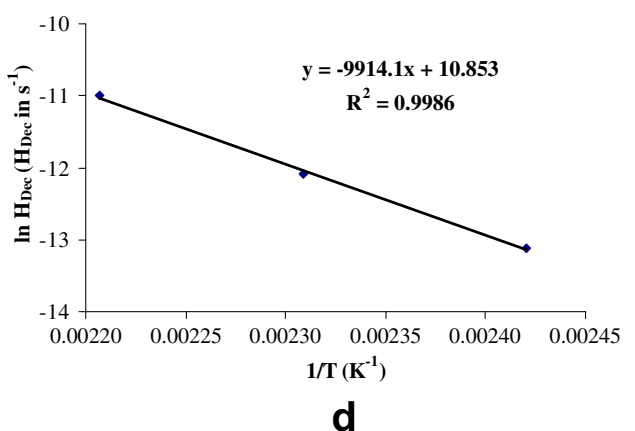

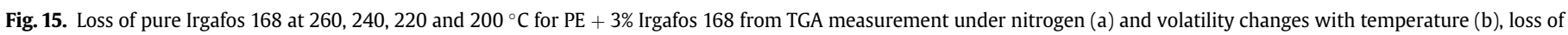
stabilizer at 180,160 and $140{ }^{\circ} \mathrm{C}$ for PE $+3 \%$ Irgafos 168 films from TGA measurement under nitrogen (c) and evaporation rate $H$ changes with temperature (d). 
Table 6

Solubility limits (expressed as weight ratio not corrected for crystallinity) as calculated by Methods 1 and 2 (see text).

\begin{tabular}{lll}
\hline$T\left({ }^{\circ} \mathrm{C}\right)$ & Method 1 & Method 2 \\
\hline 80 & 0.0045 & 0.0015 \\
120 & 0.0275 & 0.0085 \\
180 & 0.3785 & 0.0485 \\
\hline
\end{tabular}

experimental measurements for low phosphite and phosphate concentrations. In conclusion, it is acknowledged that the optimisation process could undoubtedly be improved, however, it does appear that the global trends of all aspects of the stabilization process are in fact well predicted.

The apparent activation energy of $k_{\mathrm{Dec}}$ is of the order of $100 \mathrm{~kJ} \mathrm{~mol}^{-1}$ which is in agreement with those for sulphides [21,43] in various hydrocarbon polymers, or phosphites in PP $[44,45]$ as well as for the polymer oxidation process. The fact that phosphites and sulfides keep their stabilizing efficiency over a wide temperature range is therefore not so surprising.

Finally, the model described above can be used to illustrate one important aspect of the hydroperoxide stabilization decomposers which is practically impossible to ascertain by experimental means $[46,47]$ namely the changes in $\mathrm{POOH}$ concentrations (Fig. 14) at low conversion. As expected from the kinetic equation relative to the $\mathrm{POOH}$ groups, the initial rate is negative and the curve $[\mathrm{POOH}]=f(t)$ must display a minimum as deep as the stabilizer concentration is high. In the cases studied, no $\mathrm{POOH}$ concentration lower than ca. $2 \times 10^{-5} \mathrm{~mol} \mathrm{l}^{-1}$ was reached but the time during which the $\mathrm{POOH}$ concentration remained lower than its initial value was longer as the stabilizer concentration increased. It must be recalled that if the $\mathrm{POOH}$ value is lower than a threshold value, only unimolecular $\mathrm{POOH}$ decomposition occurs and that this process is very slow compared to the bimolecular one. As a result, the stabilizing effect of $\mathrm{POOH}$ decomposers could not be predicted with a kinetic model based on a single $\mathrm{POOH}$ decomposition mechanism.

\section{Conclusions}

The stabilization of polyethylene by an organophosphite stabilizer Irgafos 168 was studied at moderate temperatures $\left(\leq 180^{\circ} \mathrm{C}\right)$. It was confirmed that phosphite is oxidized into a phosphate by reducing hydroperoxides under the reaction conditions studied. The experimental results were modelled using a scheme that had previously been established for partially soluble and volatile hydroperoxide decomposers. The kinetic parameters were tentatively determined from specific experimental data (TGA results for volatilization), theoretical considerations (for solubility) and efficiency considerations (for stabilizer-hydroperoxide rate constants). These modelling results are encouraging for several reasons: with a view to simulating kinetics, for establishing carbonyl formation as well as for the study of stabilizer depletion kinetics, and for the conversion of phosphite into the phosphate by-product.

\section{Acknowledgements}

ANR 'BioCarbMat' (Pole de compétitivité Mov'eo) is gratefully acknowledged for financial support.

\section{Appendix 1. Calculation of stabilizer evaporative loss rate}

The stabilizer evaporation rate was expressed by Calvert and Billingham [48]: $\frac{\mathrm{d} m}{\mathrm{~d} t}=-\frac{V_{0}}{[\mathrm{Dec}]_{\mathrm{sat}}}[\mathrm{Dec}]=H_{\mathrm{Dec}} \cdot[\mathrm{Dec}]$

where:

$-\mathrm{d} m / \mathrm{d} t$ is the mass of stabilizer lost per unit of time and surface $\left(\mathrm{kg} \mathrm{m}^{-2} \mathrm{~s}^{-1}\right)$.

- $V_{0}$ is the loss rate of the pure stabilizer $\left(\mathrm{kg} \mathrm{m}^{-2} \mathrm{~s}^{-1}\right)$.

When the stabilizer concentration is equal or higher than the solubility limit, this law becomes:

$\frac{\mathrm{d} m}{\mathrm{~d} t}=-V_{0}$

$H$ and $V_{0}$ were estimated in two ways:

(1) From TGA measurements for pure stabilizer evaporation. Measurements were performed for Irgafos 168 at temperature ranging from 200 to $260{ }^{\circ} \mathrm{C}$, in the liquid state (Fig. 15b).

It can be observed that:

$\frac{\mathrm{d} \Delta m / m_{0}}{\mathrm{~d} t}=-k$

which leads to:

$V_{0}=k \cdot \rho_{\text {Dec }} \cdot e$

where:

- $\rho_{\text {Dec }}$ is the stabilizer volume mass

$-e$ is the thickness of liquid stabilizer sample (deduced from initial mass, density and pan area)

$-k$ is expressed in $\mathrm{s}^{-1}$

On the assumption that $V_{0}$ obeys Arrhenius's law (Fig. 15a), and that $[\mathrm{Dec}]$ is on the same order as $[\mathrm{Dec}]_{\mathrm{sat}}$, one obtains at $80^{\circ} \mathrm{C}$ : $V_{0}$. [Dec $] /[\mathrm{Dec}]_{\text {sat }} \sim 10^{-4} \mathrm{~mol} \mathrm{l}^{-1} \mathrm{~h}^{-1}$ i.e. many factors higher than the values suggested by Fig. 13. In fact, this overestimation is not surprising since Irgafos 168 is in the liquid state during the TGA measurements and in the solid state at 80 or $120^{\circ} \mathrm{C}$.

(2) An alternative method starts from the loss rate in films stabilized with $3 \%$ Irgafos 168 at 180,160 and $140{ }^{\circ} \mathrm{C}$. Exploitation of the TGA curve gives the $H$ value such as:

$\frac{\mathrm{d} m_{\text {Dec }}}{\mathrm{d} t}=-H_{\text {Dec }} \cdot m_{\text {Dec }}$

$m_{\text {Dec }}$ is a priori estimated from the theoretical stabilizer amount. The $H$ parameter corresponds to the value used in the kinetic model (see Eqs. (14)-(16)).

Neglecting the beginning of the curve (which might correspond to some volatile impurities), the curves are seen to be almost linear (see Fig. 15c). The $H$ values at 80 and $120{ }^{\circ} \mathrm{C}$ were determined by extrapolation (Fig. 15d).

The rate of volatile loss for phosphate (denoted by $H_{\text {Dec }}=0$ ) was also added to the model in order to simulate the shape of the phosphate by-product build-up (Figs. 9 and 10). This value, which is not decisive for simulating the main trends of carbonyl formation and for stabilizer depletion kinetics in the stabilized films, was adjusted from the final $P(V)$ depletion. 


\section{Appendix 2. Calculation of solubility limits}

Two methods were employed:

(1) An estimation was made from the Flory Huggins law:

$\left.-\ln \varphi_{\text {Irgafos } 168}=\frac{\Delta H_{\mathrm{M} \text { Irgafos 168 }}}{R T} 1-\frac{T}{T_{\mathrm{M} \text { Irgafos 168 }}}\right)+\varphi_{\mathrm{PE}}+\chi \varphi_{\mathrm{PE}}^{2}$

$\chi$ being the interaction parameter given by:

$\chi=\frac{V_{\mathrm{mIrgafos} 168}}{R T} \cdot\left(\delta_{\mathrm{PE}}-\delta_{\text {Irgafos } 168}\right)^{2}$

where:

- $\phi_{\text {Irgafos }} 168$ and $\phi_{\mathrm{PE}}$ are respectively the solubility limit of Irgafos 168 in PE expressed in volume fraction and the PE volume fraction $\left(\phi_{\mathrm{PE}}=1-\phi_{\text {Irgafos } 168}\right)$.

- $\Delta H_{\mathrm{M} \text { Irgafos }} 168$ is the melting enthalpy equal to $46,900 \mathrm{~J} \mathrm{~mol}^{-1}$

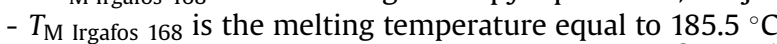

- $V_{\mathrm{m} \text { Irgafos } 168}$ is the molar volume equal to $616 \mathrm{~cm}^{3} \mathrm{~mol}^{-1}$

(2) A second method was based on the following equation. Its

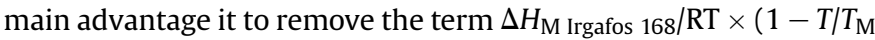
Irgafos 168 ) as a possible source of error:

$$
\begin{aligned}
\ln ( & \left.\varphi_{\text {Irgafos 168 }}\right)_{\mathrm{PP}}-\ln \left(\varphi_{\text {Irgafos 168 }}\right)_{\mathrm{PE}} \\
= & -\left(\varphi_{\text {Irgafos 168 }}\right)_{\mathrm{PE}}+\left(\varphi_{\text {Irgafos 168 }}\right)_{\mathrm{PP}}+\chi_{\mathrm{PE} / \text { Irgafos } 168} \\
& \times\left[1-\left(\varphi_{\text {Irgafos 168 }}\right)_{\mathrm{PE}}\right]^{2}-\chi_{\mathrm{PP} / \text { Irgafos } 168} \\
& \times\left[1-\left(\varphi_{\text {Irgafos 168 }}\right)_{\mathrm{PP}}\right]^{2}
\end{aligned}
$$

in which $\left(\varphi_{\text {Irgafos } 168}\right)_{\text {PP }}$ comes from values reported for PP at 60,70 and $80{ }^{\circ} \mathrm{C}$ (and extrapolated values using Arrhenius's law in which the activation energy would be $\Delta H_{\mathrm{M}}$ Irgafos $168 / R$ ).

These two equations were solved using solubility parameters values of $16 \mathrm{MPa}^{1 / 2}$ for PE, $18 \mathrm{MPa}^{1 / 2}$ for PP, and $18.5 \mathrm{MPa}^{1 / 2}$ for Irgafos 168 (which can be deduced from its solubility spectra in various common solvents [49], or predicted with the method proposed by Van Krevelen and Te Nijenhuis [50]). The calculated solubility limits (in weight ratio of amorphous phase) are given in Table 6.

The calculated solubility in weight ratio in the amorphous phase (Table 6 ) ranged between 0.1 and $0.45 \%$ at $80{ }^{\circ} \mathrm{C}$ and was above the concentrations under study for other temperatures under investigation (i.e. 120 and $180^{\circ} \mathrm{C}$ ). These values can be considered to be in good agreement with the work of Garcia-Trabajo and Billingham who reported that Irgafos 168 was highly soluble in PP contrary to previous observations [51].

In fact, available data are scarce. It has been claimed that theoretical approaches are inaccurate in many cases and any experimental method remains the object of a consensus [52]. Solubility remains the most difficult parameter to be determined. Our approach consists in determining the best value permitting a satisfying fit of the experimental curves. In other words, kinetic modelling is used as an indirect method for estimating the solubility.

\section{References}

[1] Hiatt R, Smythe RJ, McColeman C. The reaction of hydroperoxides with triphenylphosphine. Can J Chem 1971;49(10):1707-11.
[2] Scott G. Mechanism of polymer stabilization. Pure Appl Chem 1972;30(1): 267-89.

[3] Barrio L, Toribio PP, Campos-Martin JM, Fierro JLG. An experimental and theoretical study of the catalytic effect of quaternary ammonium salts on the oxidation of hydrocarbons. Tetrahedron 2004;60(50):11527-32.

[4] Pobedimskii DG, Buchachenko AL. Mechanism of the inhibiting action of phosphites and sulfides. Rus Chem Bul 1968;17(12):2579-82.

[5] Khelidj N, Colin X, Audouin L, Verdu J, Monchy-Leroy C, Prunier V. Oxidation of polyethylene under irradiation at low temperature and low dose rate. Part I. The case of "pure" radiochemical initiation. Polym Degrad Stab 2006;91(7):1593-7.

[6] Schwetlick K, Pionteck J, König T, Habicher WD. Organophosphorus antioxidants-VIII. Kinetics and mechanism of the reaction of organic phosphites with peroxyl radicals. Eur Polym J 1987;23(5):383-8.

[7] Walling C, Rabinowitz R. The reaction of trialkyl phosphites with thiyl and alkoxy radicals. J Am Chem Soc 1959;81(5):1243-9.

[8] Denney DB, Goodyear WF, Goldstein B. Concerning the mechanism of the reduction of hydroperoxides by trisubstituted phosphines and trisubstituted phosphites. J Am Chem Soc 1960;82(6):1393-5.

[9] Habicher WD, Bauer I. In: Halim Hamid S, editor. Handbook of polymer degradation. 2nd ed. New York, Basel: Marcel Dekker Inc.; 2000. p. 81.

[10] Schwetlick K, Habicher WD. Action mechanisms of phosphite and phosphonite stabilizers. In: Clough RL, Billingham N, Gillen KT, editors. Polymer durability. Advances in Chemistry Series, vol. 249. Washington: American Chemical Society; 1996. p. 349.

[11] Kriston I, Orbán-Mester A, Nagy G, Staniek P, Földes E, Pukánszky B. Melt stabilisation of Phillips type polyethylene, Part II: correlation between additive consumption and polymer properties. Polym Degrad Stab 2009;94(9): $1448-56$.

[12] Kriston I, Pénzes G, Szijjártó G, Szabó P, Staniek P, Földes E, et al. Study of the high temperature reactions of a hindered aryl phosphite (Hostanox PAR 24) used as a processing stabiliser in polyolefins. Polym Degrad Stab 2010;95(9): 1883-93.

[13] Kriston I, Orbán-Mester A, Nagy G, Staniek P, Földes E, Pukánszky B. Melt stabilisation of Phillips type polyethylene, Part I: the role of phenolic and phosphorous antioxidants. Polym Degrad Stab 2009;94(4):719-29.

[14] Chirinos-Padrón AJ, Hernández PH, Allen NS, Vasilion C, Marshall GP, de Poortere M. Synergism of antioxidants in high density polyethylene. Polym Degrad Stab 1987;19(2):177-89.

[15] Schwarzenbach K, Gilg B, Muller D, Knobloch G, Pauquet JR, Rota-Graziosi P, et al. In: Zweifel $\mathrm{H}$, editor. Plastics additives handbook. 5th ed. Cincinnati: Hanser Gardner Publications; 2001, p. 1.

[16] Al-Malaika S, Goodwin C, Issenhuth S, Burdick D. The antioxidant role of $\alpha$ tocopherol in polymers II. Melt stabilising effect in polypropylene. Polym Degrad Stab 1999;64(1):145-56.

[17] Verdu J, Rychly J, Audouin L. Synergism between polymer antioxidants Kinetic modelling. Polym Degrad Stab 2003;79(3):503-9.

[18] Zweifel $\mathrm{H}$. Effect of stabilization of polypropylene during processing and its influence on long term behavior under thermal stress. In: Clough RL Billingham N, Gillen KT, editors. Polymer durability. Advances in Chemistry Series, vol. 49. Washington: American Chemical Society; 1996. p. 375.

[19] Bauer I, Habicher WD, Rautenberg C, Al-Malaika S. Antioxidant interaction between organic phosphites and hindered amine light stabilisers during processing and thermoxidation of polypropylene. Polym Degrad Stab 1995; 48(3):427-40.

[20] Khelidj N, Colin X, Audouin L, Verdu J, Monchy-Leroy C, Prunier V. Oxidation of polyethylene under irradiation at low temperature and low dose rate. Part II. Low temperature thermal oxidation. Polym Degrad Stab 2006;91(7):1598-605.

[21] Richaud E, Colin X, Monchy-Leroy C, Audouin L, Verdu J. Kinetic modelling of stabilization coupled with stabilizer loss by evaporation. Case of dithioester stabilized polyethylene. Polym Degrad Stab 2009;94(11):2004-14.

[22] Richaud E, Fayolle F, Verdu J. Polypropylene stabilization by hindered phenols - Kinetic aspects. Polym Degrad Stab 2011:96(1):1-11.

[23] Billingham NC, Garcia-Trabajo P. Physical chemistry of a phosphite processing stabilizer in polypropylene: Part 1: solubility. Polym Eng Sci 2001;41(3): 417-25

[24] Földes E, Maloschik E, Kriston I, Staniek P, Pukánszky B. Efficiency and mechanism of phosphorous antioxidants in Phillips type polyethylene. Polym Degrad Stab 2006;91(3):479-87.

[25] Djouani F, Richaud E, Fayolle B, Verdu J. Investigation of model fuel effects on thermal oxidation of polyethylene. AIP Conf. Proc 2010;1255:7-9.

[26] Rugg FM, Smith JJ, Bacon RC. Infrared spectrophotometric studies on polyethylene. II. Oxidation. J Polym Sci 1954;13(72):535-47.

[27] Richaud E, Colin X, Monchy-Leroy C, Audouin L, Verdu J. Polyethylene stabilization against thermal oxidation by a trimethylquinoleine oligomer. Polym Degrad Stab 2009;94(3):410-20.

[28] Zeynalov EB, Allen NS. Modelling light stabilizers as thermal antioxidants. Polym Degrad Stab 2006;91(12):3390-6.

[29] Schwetlick K, Pionteck J, Winkler A, Hähner U, Kroschwitz H, Habicher WD. Organophosphorus antioxidants: Part X - Mechanism of antioxidant action of aryl phosphites and phosphonites at higher temperatures. Polym Degrad Stab 1991;31(2):219-28.

[30] Peinado C, Corrales T, García-Casas MJ, Catalina F, Ruiz Santa Quiteria V, Parellada MD. Chemiluminescence from poly(styrene-b-ethylene-cobutylene-b-styrene) (SEBS) block copolymers. Polym Degrad Stab 2006; 91(4):862-74 
[31] Ortuoste N, Allen NS, Papanastasiou M, McMahon A, Edge M, Johnson B, et al. Hydrolytic stability and hydrolysis reaction mechanism of bis(2,4-di-tertbutyl)pentaerythritol diphosphite (Alkanox P-24). Polym Degrad Stab 2006; 91(1):195-211.

[32] Tocháček J, Jiří Sedlář J. Effect of hydrolysability and structural features of phosphites on processing stability of isotactic polypropylene. Polym Degrad Stab 1993;41(2):177-84.

[33] Schwetlick K, König T, Rüger C, Pionteck J, Habicher WD. Chain-breaking antioxidant activity of phosphite esters. Polym Degrad Stab 1986;15(2): 97-108.

[34] Denisov ET, Afanas'ev IB. Oxidation and antioxidants in organic chemistry and biology. Boca Raton, London, New York, Singapore: CBC Taylor \& Francis Group; 2005. p. 573.

[35] Neri C, Costanzi S, Riva RM, Farris R, Colombo R. Mechanism of action of phosphites in polyolefin stabilisation. Polym Degrad Stab 1995;49(1): 65-9.

[36] Navarro R, Audouin L, Verdu J. Reactions of antioxidants with molecular oxygen. Part I. 2,2'-methylene-bis(4-methyl-6-tert-butylphenol) in silicone matrix. Polym Degrad Stab 2011;96(2):220-5.

[37] Scheirs J, Pospíšil J, O'Connor MJ, Bigger SW. Characterisation of conversion products formed during degradation of processing antioxidants. In: Clough RL, Billingham N, Gillen KT, editors. Polymer durability. Advances in Chemistry Series, vol. 219. Washington: American Chemical Society; 1996. p. 349.

[38] Schwetlick K, König T. Antioxidant action of phosphite, sulfite and borate esters - A comparison. Polym Degrad Stab 1989;24(4):279-87.

[39] Naskar K, Kokot D, Noordermeer JWM. Influence of various stabilizers on ageing of dicumyl peroxide-cured polypropylene/ethylene-propylene-diene thermoplastic vulcanizates. Polym Degrad Stab 2004;85(2):831-9.

[40] Humphris KJ, Scott G. Mechanisms of antioxidant action. Phosphite esters. Pure Appl Chem 1973;36(1):163-76.

[41] Richaud E, Colin X, Fayolle B, Audouin L, Verdu J. Induction period in the lowtemperature thermal oxidation of saturated hydrocarbons: example of polyethylene. Int J Chem Kin 2008;40(12):769-77.
[42] Van Krevelen DW, Te Nijenhuis K. Properties of polymers, their correlation with chemical structure; their numerical estimation and prediction from additive group contributions. 4th ed. Amsterdam: Elsevier; 2009. p. 655.

[43] Colin X, Audouin L, Verdu J, Le Huy M. Kinetic modelling of the thermal oxidation of polyisoprene elastomers. Part 2: effect of sulfur vulcanization on mass changes and thickness distribution of oxidation products during thermal oxidation. Polym Degrad Stab 2007;92(5):898-905.

[44] Sarrabi S, Colin X, Tcharkhtchi A. Kinetic modeling of polypropylene thermal oxidation during its processing by rotational molding. J Appl Polym Sci 2010; 118(2):980-96.

[45] E, Durabilité des Géotextiles en Polypropylène. Thèse de doctorat. ENSAM de Paris. 2006.

[46] Carlsson DJ, Lacoste J. A critical comparison of methods for hydroperoxide measurement in oxidized polyolefins. Polym Degrad Stab 1991;32(3):377-86.

[47] Gardette JL, Lemaire J. Advantages and limits of hydroperoxide titration methods in solid polymers. Polym Photochem 1986;7(5):409-16.

[48] Calvert PD, Billingham NC. Loss of additives from polymers: a theoretical model. J Appl Polym Sci 1979;24(2):357-70.

[49] Available from: http://www.bjmytimes.com/ciba/ciba/IRGAFOS168.pdf.

[50] Van Krevelen DW, Te Nijenhuis K. Properties of polymers, their correlation with chemical structure; their numerical estimation and prediction from additive group contributions. 4th ed. Amsterdam: Elsevier; 2009. p. 189.

[51] Spatafore R, Pearson L. Migration and blooming of stabilizing antioxidants in polypropylene. Polym Eng Sci 1991;31(22):1610-7.

[52] Billingham N. In: Zweifel H, editor. Plastics additives handbook. 5th ed. Cincinnati: Hanser Gardner Publications; 2001. p. 1019.

[53] Latocha C, Maria Uhniat M. Usability analysis of a simplified kinetic equation for evaluation of antioxidant action in LDPE. Polym Degrad Stab 1992;35(2):115-20.

[54] Setnescu T, Jipa S, Setnescu R, Mihalcea I. Synergistic effects of some phenolic inhibitors used in polyethylene stabilization-II. Oxyluminescence method for studying the synergistic effects of some binary mixtures of phenolic stabilizers. Polym Degrad Stab 1996;52(1):19-23.

[55] Gugumus F. Critical antioxidant concentrations in polymer oxidation-II. Experimental 'proofs' *. Polym Degrad Stab 1998;60(1):99-117. 